\title{
BIOGRAFSKO-NARATIVNI METODOLOŠKI PRISTOP ZA POUČEVANJE IN RAZUMEVANJE VSEBIN SLOVENSKEGA IZSELJENSTVA
}

\section{dr. Mojca Ilc Klun}

Oddelek za geografijo, Filozofska fakulteta Univerze v Ljubljani

Aškerčeva 2, I000 Ljubljana

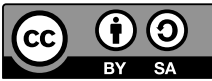

e-pošta: mojca.ilc@ff.uni-lj.si

Izvirni znanstveni članek

COBISS 1.01

DOI: $10.4312 /$ dela.48.2.61-76

\section{Izvleček}

Prispevek prikazuje uporabnost biografsko-narativnega metodološkega pristopa pri poučevanju, razumevanju in vrednotenju vsebin slovenskega izseljenstva. Prepričani smo, da lahko preko omenjenega metodološkega pristopa mlade učinkoviteje poučujemo o vsebinah slovenskega izseljenstva in s tem pristopom pri mladih vzbudimo željo po raziskovanju omenjene tematike.

Ključne besede: migracije, slovensko izseljenstvo, vzgojno-izobraževalni sistem, biografsko-narativni metodološki pristop, življenjske zgodbe

\section{BIOGRAPHIC-NARRATIVE METHODOLOGICAL APPROACH FOR TEACHING AND UNDERSTANDING THE CONTENTS OF SLOVENIAN EMIGRATION}

\begin{abstract}
The article presents the biographic-narrative methodological approach (BINM), which can be used for teaching, understanding and evaluating the topic of Slovenian emigration. We think that through BINM approach young people can more effectively learn about the topic of Slovenian emigration and it can motivate them for their own research.
\end{abstract}

Keywords: migration, Slovenian emigration, educational system, biographic-narrative approach (BINM approach), life stories 


\section{UVOD}

Migracijski tokovi imajo dolgo zgodovino; po nekaterih podatkih lahko govorimo o migracijskih tokovih vse od razseljevanja prvega oziroma modernega človeka dalje (Bellwood, 2013). Napovedi kažejo, da bodo migracijski tokovi v prihodnosti neprimerljivo večji in obsežnejši kot v preteklosti (Kovač, 2003). Že 20. stoletje je bilo zaradi obsežnih migracijskih tokov proglašeno za »stoletje mobilnosti« (Papademetriou, 2007) oziroma »stoletje migracij« (Castles, Miller, 2009). Leta 2010 je bilo po podatkih Združenih narodov na svetu 200 milijonov mednarodnih migrantov (Salzmann, Edmonston, Raymer, 2010), leta 2013232 milijonov, leta 2015 pa že 244 milijonov (International migration report 2015, 2016).

Teme, povezane z migracijami, bi morale postati pomembna učna vsebina tudi v slovenskih vzgojno-izobraževalnih inštitucijah, ne le zaradi sodobnih migracijskih tokov 21. stoletja, pač pa tudi zaradi vpetosti prostora današnje Republike Slovenije v procese migracij (Pajnik, Zavratnik Zimic, 2003). Na demogeografsko podobo prostora današnje Republike Slovenije so na eni strani pomembno vplivali izselitveni tokovi (samo v obdobju od konca 19. stoletja do začetka prve svetovne vojne se je s slovenskega ozemlja izselilo okoli 300.000 ljudi, kar je bila takrat tretjina vseh prebivalcev današnjega slovenskega prostora; Drnovšek, 1991), prav tako pa so na sodobno demogeografsko podobo Slovenije močno vplivala tudi priseljevanja ljudi z območja nekdanje Jugoslavije po letu 1960. Kljub temu, da je slovenski narod eden izmed manjših evropskih narodov, naj bi po nekaterih podatkih izven meja današnje Slovenije živelo okoli 500.000 ljudi s slovenskimi koreninami (Klemenčič, 1995).

V slovenskih osnovnošolskih in srednješolskih učnih načrtih različnih šolskih predmetov lahko beremo, da tekom vzgojno-izobraževalnega procesa mlade vzgajamo $\mathrm{k}$ spoštovanju različnosti in strpnosti, da pri pouku dobijo pomembna znanja, spretnosti in sposobnosti, s katerimi lahko razumejo ožje in širše okolje in družbo, razvijajo pozitivna stališča do kulturne različnosti in razvijajo medkulturne odnose (Učni načrt. Geografija ..., 2011; Učni načrt. Zgodovina ..., 2011; Učni načrt. Državljanska ..., 2011; Učni načrt. Družba ..., 2011; Učni načrt. Sociologija ..., 2008). Vse te globalne učne cilje lahko v slovenskem vzgojno-izobraževalnem procesu dosežemo s poučevanjem o migracijah oziroma s poučevanjem o vsebinah slovenskega izseljenstva. Menimo namreč, da je poznavanje in razumevanje lastnih migracij skozi zgodovino in v sedanjosti pogoj za razumevanje in vrednotenje sodobnih migracijskih tokov in vpetosti slovenskega prostora $\mathrm{v}$ globalne in evropske selitvene tokove. Vprašanje, ki se tu poraja, pa je, s pomočjo katerih učnih metod in učil naj učitelji v šolah poučujejo o tematikah slovenskega izseljenstva svoje učence in dijake, da bo obravnava omenjenih tematik aktualnejša, zanimivejša in bo tako prispevala k celovitejšemu poznavanju slovenskega izseljenstva in obenem tudi globalnega konteksta migracij.

Slovenci so se z območja današnje Slovenije množičneje selili predvsem v treh valovih - konec 19. in v začetku 20. stoletja; med in po drugi svetovni vojni ter v 60. in 70. letih 20. stoletja (Drnovšek, 1991). Dejstvo je, da so ta zgodovinska obdobja slovenskega izseljevanja precej časovno odmaknjena od današnje učeče se mladine, zato svoje 
predstave o slovenskem izseljenstvu razvijajo predvsem na podlagi njim predstavljenih virov, prikazov in informacij. Pomembno je, kako bo učitelj te vsebine pri pouku predstavil, kaj o slovenskem izseljenstvu bo izpostavil in katere učne metode in učila bo za to uporabil. Na podlagi tega bodo učenci razvili svoje predstave o slovenskem izseljenstvu. Nekateri bodo svoje predstave razvili na podlagi izkušenj iz domačega okolja, redkeje pa na podlagi lastnega dela na terenu (obiska slovenskih izseljenskih skupnosti v različnih državah). In ravno zato je pomembno, kako in na kakšen način so vsebine slovenskega izseljenstva $\mathrm{v}$ šolah predstavljene.

\section{METODOLOŠKI PRISTOP}

Biografsko-narativni metodološki pristop je kvalitativni raziskovalni metodološki pristop (Wengraf, 2004) in je ena izmed oblik nestrukturiranega poglobljenega intervjuja. Razvil se je kot inovativen metodološki pristop, s pomočjo katerega so pojasnjevali različne družbene pojave, med drugim tudi pojave, ki so (bili) povezani z migracijami. Že v 18. in 19. stoletju so v okviru zgodovinske stroke uporabljali različna pisma, dnevnike, osebna pričevanja, fotografije (t. i. biografske vire), da bi z njimi lažje pojasnjevali posamezne pomembne družbene dogodke (Pajnik, Bajt, 2009). V zadnjem času so ta metodološki pristop aplicirali tudi na druge znanstvene vede, na primer na psihologijo (Randall in sod., 2015), antropologijo (Blix in sod., 2013; Blix in sod., 2015), njegova uporaba pa je vse bolj v porastu tudi v študijah spolov (Roseneil, 2012; Russell, 2012; Willemse, 2014) in pri preučevanju migracijskih procesov (Crivello, 2015; Laoire, 2007; Meares, 2010; Pajnik, Bajt, 2009). Biografsko-narativni metodološki pristop omogoča pri raziskovanju migracij »empirično obravnavo kompleksnosti, raznolikosti in spremenljivosti migracij tako, da poudari individualne izkušnje« (Pajnik, Bajt, 2009, str. 74). V sklopu biografsko-narativnega metodološkega pristopa nas torej zanima osebna izkušnja pripovedovalca, njegova interpretacija družbenih dogodkov. Prav zaradi tega je treba poudariti, da je končni rezultat tega pristopa, napisana življenjska zgodba, osebno doživljanje in oseben pogled pripovedovalca na posamezne družbene dogodke, ki pa niso nujno v skladu z mnenjem večine. Poudariti je treba tudi, da pripovedovalec pri pripovedovanju svoje življenjske zgodbe izpostavi samo zanj pomembne dogodke oziroma tiste, ki se mu zdijo za zgodbo pomembni (Bamberg, 2011). Bamberg (2011) je izpostavil, da življenjske zgodbe niso statične, ampak se lahko spreminjajo; pripovedovalec jih pove z namenom in za določeno poslušalstvo (Bamberg, 2011).

$\mathrm{Z}$ biografsko-narativnim metodološkim pristopom želimo intervjuvanca spodbuditi, da nam zaupa in s svojimi besedami pove svojo doživeto življenjsko zgodbo, saj je osnovni namen tega pristopa ta, da poskušamo rekonstruirati družbene dogodke skozi perspektivo intervjuvanca, ki to zgodbo oziroma opis poda. Poudariti je treba, da se pri tem metodološkem pristopu osredotočamo na življenjsko zgodbo posameznika, na njegovo osebno izkušnjo, torej na njegovo osebno doživljanje družbenih procesov. Zato je intervjuvar v vlogi aktivnega poslušalca, torej tistega, ki v osrednjo fazo tega metodološkega pristopa (faza osrednje pripovedi) ne posega, ampak dovoli in pusti intervjuvancu, da s svojimi besedami pove svojo življenjsko zgodbo oziroma njen del. Eden izmed razvijalcev biografsko-narativnega metodološkega pristopa, Tom Wengraf, poudarja, da je 
pri tem metodološkem pristopu ključnega pomena izhodiščno vprašanje (stavek), ki ga intervjuvar zastavi tako, da intervjuvanca spodbudi, da pove svojo doživeto življenjsko zgodbo (Wengraf, 2004).

Pajnik in Bajt (2009) v svojem delu »Biografski narativni intervju: aplikacija na študije migracij « navajata, da mora za uspešen potek biografsko-narativnega metodološkega pristopa intervjuvar slediti šestim fazam. Prva faza je t. i. predfaza, v okviru katere se mora intervjuvar temeljito pripraviti na začetek izvedbe samega intervjuja. To pomeni, da mora dobro preučiti tematiko raziskovanja, torej njeno širšo vsebino, katere osebno interpretacijo bo potem raziskoval v okviru intervjuja. Prav tako je pomembno, da se v predfazi intervjuvar in intervjuvanec srečata in spoznata ${ }^{1}$, vzpostavita zaupanje, ter da intervjuvar intervjuvancu pojasni potek in namen raziskave (intervjuja). V predfazi je nujno tudi, da intervjuvar zagotovi anonimnost intervjuja. Le na tak način bo preprečil morebitne strahove intervjuvanca pred deljenjem njegove osebne življenjske pripovedi. Nato sledi druga faza, ki je začetna faza, torej faza začetka intervjuja. V tej fazi intervjuvar še enkrat pojasni intervjuvancu potek intervjuja, predstavi osrednjo temo razgovora, še enkrat zagotovi anonimnost in v začetku intervjuja zastavi intervjuvancu izhodiščno vprašanje oziroma poved, ki spodbudi pripoved življenjske zgodbe intervjuvanca. V osrednji fazi intervjuvanec nemoteno pripoveduje svojo življenjsko zgodbo, svoj pogled na raziskovalno temo, svoje doživljanje. V tej fazi intervjuvar ne posega v pripoved intervjuvanca, pač pa si morebitna vprašanja, pomisleke samo beleži. Pomembno je, da v tej fazi intervjuvanec svoje doživljanje zgodbe pove nemoteno, brez posegov intervjuvarja, ki je v tej fazi samo v vlogi aktivnega poslušalca. Ko intervjuvanec samostojno zaključi s pripovedovanjem, sledi faza vprašanj. $V$ tej fazi intervjuvar intervjuvancu zastavlja vprašanja, ki so se mu porodila med pripovedovanjem intervjuvanca. Poudariti je potrebno, da naj v tej fazi intervjuvar samo zastavlja vprašanja, ki se navezujejo na pripoved intervjuvanca in raziskovalno temo, nikakor pa naj v tej fazi intervjuvar ne izraža svojega lastnega mnenja ali prepričanja $\mathrm{v}$ zvezi z raziskovalno tematiko, saj bi to lahko vplivalo na intervjuvanca. Sledi zaključna faza, ko intervjuvar intervjuvancu nakaže zaključek intervjuja. Med njima lahko po zaključku intervjuja steče še neformalni razgovor.

Vsem zgoraj opisanim fazam smo sledili v procesu naše raziskave »Zgodbe in spomini ljudi slovenskih korenin v ZDA, Kanadi, Avstraliji in na Novi Zelandiji«, ki je potekala v študijskem letu 2014/2015 v okviru vaj iz študijskih predmetov Geografija Severne Amerike in Geografija Avstralije in Oceanije. V proces izvedbe raziskave so bili vključeni tudi študenti univerzitetnega študijskega programa geografija, posamezne faze naše raziskave pa so opisane v tretjem stolpcu Preglednice 1. Kot nadgradnjo biografsko-narativnemu metodološkemu pristopu smo v okviru naše raziskave zaključni fazi za potrebe vzgojno-izobraževalnega procesa dodali še šesto fazo, ki smo jo poimenovali faza pisanja zgodbe za potrebe vzgoje in izobraževanja. Ta faza ne poteka v sklopu izvedbe samega intervjuja, je pa ključna, da informacije in pripoved, ki jih je intervjuvar pridobil od intervjuvanca, v obliki zgodbe postanejo učilo, ki ga lahko učinkovito uporabimo za razumevanje in učenje določenih vsebin. V tej fazi intervjuvar združi vse informacije,

1 V primeru osebnega intervjuja je srečanje osebno, v primeru intervjuja na daljavo pa poteka "srečanje" $\mathrm{s}$ pomočjo drugih komunikacijskih kanalov (telefon, socialna omrežja ipd.). 
ki mu jih je med intervjujem zaupal intervjuvanec, jih uredi v smiselno pripoved, torej oblikuje iz informacij zgodbo, ki jo zapiše v prvi osebi ednine. Pri pisanju zgodbe naj intervjuvar pazi na jezikovne posebnosti, torej naj bo zgodba napisana jezikovno in slogovno primerno za bralca zgodbe. Ker je bilo v našem primeru izhodišče uporaba življenjskih zgodb v vzgojno-izobraževalne namene, smo pazili, da so življenjske zgodbe napisane $\mathrm{v}$ preprostem jeziku in slogu, saj smo zgodbe razvijali za osnovnošolsko in srednješolsko populacijo. Tako kot sama vsebina zgodbe je pomemben tudi naslov, ki ga je v našem primeru na podlagi vsebine zgodbe določil intervjuvar. Da bi zgodba že pred branjem pritegnila učence in dijake za nadaljnje branje, smo sklenili, da mora biti naslov poveden in zanimiv, tak, ki bo bralca, torej osnovnošolca ali srednješolca pritegnil k branju življenjske zgodbe. V našem primeru je bila izbira naslova zgodbe subjektivna izbira intevjuarja in pisca zgodbe, ki je skušal že v naslovu izpostaviti posebnost vsebine življenjske zgodbe. Kot smo že prej poudarili, mora intervjuvar pri pisanju zgodbe paziti, da se v zgodbi ohrani anonimnost intervjuvanca. To pomeni, da so v zgodbi spremenjena osebna imena, vsi ostali podatki pa so v napisani zgodbi resnični.

Preglednica 1: Faze poteka biografsko-narativnega metodološkega pristopa in opis posameznih faz v okviru raziskave "Zgodbe in spomini ljudi slovenskih korenin iz ZDA, Kanade, Avstralije in Nove Zelandije«.

Table 1: Phases of biografic-narrative methodological approach and description of phases within our research.

\begin{tabular}{|c|c|c|}
\hline FAZA & OSNOVNE ZNAČILNOSTI & $\begin{array}{l}\text { OPIS POTEKA RAZISKAVE } \\
\text { »Zgodbe in spomini ljudi slovenskih korenin iz } \\
\text { ZDA, Kanade, Avstralije in Nove Zelandije« } \\
\text { PO POSAMEZNIH FAZAH }\end{array}$ \\
\hline $\begin{array}{l}\text { 1. PREDFAZA = } \\
\text { faza priprave } \\
\text { intervjuvarja in } \\
\text { graditev zaupanja } \\
\text { intervjuvanec- } \\
\text { intervjuvar }\end{array}$ & $\begin{array}{l}\text { - } \text { Intervjuvar spozna, preuči in razu- } \\
\text { me tematiko raziskovanja; } \\
\text { - } \text { intervjuvar spozna in razume potek } \\
\text { biografsko-narativnega metodolo- } \\
\text { škega pristopa; } \\
\text { - } \text { intervjuvar in intervjuvanec se } \\
\text { spoznata, intervjuvar razloži na- } \\
\text { men raziskave, dogovorita se za } \\
\text { čas (in kraj) srečanja; } \\
\text { - } \text { med intervjuvarjem in intervjuvan- } \\
\text { cem se vzpostavi zaupanje; } \\
\text { - } \text { intervjuvar zagotovi anonimnost } \\
\text { intervjuja. }\end{array}$ & $\begin{array}{l}\text { Na skupnem srečanju oktobra } 2014 \text { in } \\
\text { februarja } 2015 \text { je intervjuvarjem pojasnjen } \\
\text { biografsko-narativni metodološki pristop in } \\
\text { namen raziskave. Intervjuvarji se seznanijo } \\
\text { s tematiko slovenskega izseljenstva in } \\
\text { diaspore v Severni Ameriki, Avstraliji in } \\
\text { na Novi Zelandiji. Intervjuvarji s pomočjo } \\
\text { sorodstvenih in prijateljskih vezi, spletnih } \\
\text { forumov, telefonskih klicev, medmrežja in } \\
\text { socialnih omrežij poiščejo in navežejo stik z } \\
\text { intervjuvanci (pripadniki slovenske diaspore) } \\
\text { ter se dogovorijo za potek intervjuja. }\end{array}$ \\
\hline $\begin{array}{l}\text { 2. ZAČETNA } \\
\text { FAZA = faza začetka } \\
\text { intervjuja }\end{array}$ & $\begin{array}{l}\text { - Intervjuvar predstavi intervjuvancu } \\
\text { osrednjo temo in ponovno zagoto- } \\
\text { vi anonimnost njegove pripovedi; } \\
\text { - } \text { intervjuvar pojasni potek razgo- } \\
\text { vora; } \\
\text { - } \\
\text { intervjuvar zastavi izhodiščno vpra- } \\
\text { šanje oziroma poved, ki spodbudi } \\
\text { pripoved življenjske zgodbe. }\end{array}$ & $\begin{array}{l}\text { Intervjuvarji intervjuvancem predstavijo } \\
\text { osrednjo temo raziskave in jim zagotovijo } \\
\text { anonimnost v raziskavi. Intervjuvancem } \\
\text { predstavijo izhodiščno poved (»Prosim } \\
\text { vas, če mi lahko zaupate vašo življenjsko } \\
\text { zgodbo, predvsem tiste dele, ki so povezani } \\
\text { s Slovenijo.«), ki spodbudi pripovedovanje } \\
\text { njihove življenjske zgodbe. }\end{array}$ \\
\hline
\end{tabular}




\begin{tabular}{|c|c|c|}
\hline FAZA & OSNOVNE ZNAČILNOSTI & $\begin{array}{l}\text { OPIS POTEKA RAZISKAVE } \\
\text { »Zgodbe in spomini ljudi slovenskih korenin iz } \\
\text { ZDA, Kanade, Avstralije in Nove Zelandije« } \\
\text { PO POSAMEZNIH FAZAH }\end{array}$ \\
\hline $\begin{array}{l}\text { 3.OSREDNJA } \\
\text { FAZA = faza } \\
\text { osrednje pripovedi, } \\
\text { faza pripovedi } \\
\text { življenjske zgodbe }\end{array}$ & 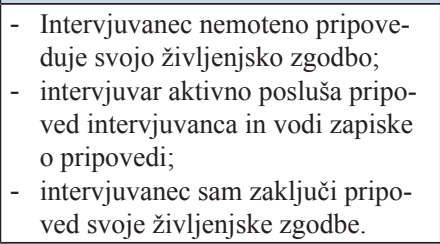 & $\begin{array}{l}\text { Intervjuvarji predajo besedo intervjuvancem, } \\
\text { ki s svojimi besedami povedo oziroma } \\
\text { opišejo svojo življenjsko zgodbo. Intervjuvar } \\
\text { med pripovedovanjem aktivno posluša, si } \\
\text { dela zapiske o pripovedi in beleži morebitna } \\
\text { vprašanja za kasnejše faze. }\end{array}$ \\
\hline $\begin{array}{l}\text { 4.FAZA VPRAŠANJ } \\
=\text { faza vprašanj s } \\
\text { strani intervjuvarja }\end{array}$ & $\begin{array}{l}\text { - Intervjuvar po tem, ko intervjuva- } \\
\text { nec zaključi s svojo pripovedjo, } \\
\text { le-temu zastavi vprašanja glede na } \\
\text { njegovo pripoved; } \\
\text { - } \text { intervjuvar se pri zastavljanju } \\
\text { vprašanj izogiba izražanju lastne- } \\
\text { ga mnenja ali prepričanja, saj bi } \\
\text { le-to lahko vplivalo na intervju- } \\
\text { vanca. }\end{array}$ & $\begin{array}{l}\text { Po končani pripovedi življenjske zgodbe } \\
\text { intervjuvarji zastavijo morebitna porajajoča } \\
\text { se vprašanja intervjuvancem. Vprašanja } \\
\text { zastavijo na podlagi svojih zapiskov med } \\
\text { pripovedjo ali splošnih vprašanj, ki so bila } \\
\text { predstavljena v okviru uvodnega srečanja z } \\
\text { intervjuvarji. }\end{array}$ \\
\hline $\begin{array}{l}\text { 5.ZAKLJUČNA } \\
\text { FAZA = faza } \\
\text { zaključka intervjuja } \\
\text { in neformalnega } \\
\text { pogovora }\end{array}$ & $\begin{array}{l}\text { - Intervjuvar nakaže konec interv- } \\
\text { juja; } \\
\text { - med intervjuvarjem in intervjuvan- } \\
\text { cem lahko steče nadaljnji nefor- } \\
\text { malni pogovor; } \\
\text { - intervjuvar zabeleži pridobljene } \\
\text { podatke. }\end{array}$ & $\begin{array}{l}\text { Intervjuvarji zaključijo intervju in, če se } \\
\text { nakaže potreba, z intervjuvanci nadaljujejo } \\
\text { neformalni pogovor. Intervjuvarji takoj po } \\
\text { zaključku intervjuja zabeležijo pridobljene } \\
\text { podatke. }\end{array}$ \\
\hline $\begin{array}{l}\text { 6.FAZA = } \\
\text { dodatna faza, faza } \\
\text { pisanja zgodbe za } \\
\text { potrebe vzgoje in } \\
\text { izobraževanja mladih }\end{array}$ & $\begin{array}{l}\text { - Intervjuvar glede na zapiske in } \\
\text { opravljen intervju napiše življenj- } \\
\text { sko zgodbo intervjuvanca. }\end{array}$ & $\begin{array}{l}\text { Dodatna faza, v kateri intervjuvarji takoj } \\
\text { po zaključku intervjuja zapišejo življenjsko } \\
\text { zgodbo intervjuvanca. V zgodbi morajo } \\
\text { obvezno paziti na resničnost pridobljenih } \\
\text { podatkov, pravilen zapis in anonimnost } \\
\text { intervjuvanca. Življenjsko zgodbo } \\
\text { intervjuvanca napišejo za potrebe vzgojno- } \\
\text { izobraževalnega procesa, tj. pouka v } \\
\text { osnovni in srednji šoli. Zgodbo napišejo } \\
\text { v prvi osebi ednine, torej kot bi zgodbo } \\
\text { pripovedoval v celoti intervjuvanec. }\end{array}$ \\
\hline
\end{tabular}

Vir/Source: Pajnik, Bajt, 2009; Ilc Klun 2017.

Zaradi precejšnje prostorske oddaljenosti na relaciji intervjuvanec - intervjuvar smo se poslužili sodobne informacijsko komunikacijske tehnologije ter nekatere intervjuje izpeljali tudi s pomočjo pogovorov preko mobilnih in spletnih aplikacij (Viber, Skype, Facebook).

S pomočjo biografsko-narativnega metodološkega pristopa smo dobili podatke, ki smo jih uporabili pri sestavi novih učil za poučevanje o vsebinah slovenskega izseljenstva in diaspore. Naše izhodišče raziskave je bilo namreč tudi, da lahko vsebine slovenskega izseljenstva in diaspore v slovenskem osnovnem in srednješolskem vzgojno-izobraževalnem 
sistemu poučujemo tudi preko doživetih življenjskih zgodb slovenskih izseljencev oziroma njihovih potomcev.

\section{VKLJUČENOST TEMATIK SLOVENSKEGA IZSELJENSTVA V FORMALNI VZGOJNO-IZOBRAŽEVALNI OKVIR V REPU- BLIKI SLOVENIJI}

Da bi lahko ovrednotili vključenost tematik slovenskega izseljenstva v slovenskem vzgojno-izobraževalnem sistemu, smo opravili tri obsežnejše raziskave. Najprej smo z vidika zastopanosti vsebin slovenskega izseljenstva in diaspore analizirali veljavne učne načrte izbranih obveznih osnovnošolskih in srednješolskih predmetov (geografija, zgodovina, družba, državljanska in domovinska vzgoja ter etika, sociologija), za katere smo predvidevali, da bi se lahko glede na osrednjo učno tematiko v njih pojavljale vsebine slovenskega izseljenstva. V prvi fazi raziskave smo opravili kvantitativno analizo učnih načrtov omenjenih osnovnošolskih in srednješolskih predmetov, kjer smo v posameznem učnem načrtu preštevali število izbranih presojevalnih kategorij ${ }^{2}$ (referenc), ki se navezujejo na vsebinsko področje slovenskega izseljenstva in diaspore. V drugi fazi analize učnega načrta pa je sledilo kvalitativno vrednotenje, v okviru katerega nas je zanimala predvsem vsebina operativnih učnih ciljev, ki so zapisani v posameznem dokumentu in se nanašajo na področje slovenskega izseljenstva in diaspore. Rezultati obeh analiz so pokazali, da lahko z vidika zastopanosti vsebin slovenskega izseljenstva in diaspore učne načrte razvrstimo v tri skupine. Prva skupina predstavlja učne načrte, ki ne vključujejo operativnih učnih ciljev s splošnimi vsebinami migracij, niti z vsebinami slovenskega izseljenstva in diaspore (osnovnošolski učni načrt za geografijo, osnovnošolski učni načrt za državljansko in domovinsko vzgojo ter etiko, srednješolski učni načrt za sociologijo), druga skupina učne načrte, katerih operativni učni cilji vključujejo vsebine o splošnih migracijskih procesih, a ne vsebin slovenskega izseljenstva in diaspore (osnovnošolski učni načrt za zgodovino), tretja skupina pa učne načrte za tiste šolske predmete, katerih operativni učni cilji vsebujejo tako vsebine, ki so vezane na splošne migracijske procese, kot vsebine slovenskega izseljenstva in diaspore (učni načrt za geografijo za splošno, klasično in ekonomsko gimnazijo, učni načrt za geografijo za strokovno gimnazijo, učni načrt za zgodovino za splošno gimnazijo, učni načrt za zgodovino za klasično gimnazijo, učni načrt za zgodovino za strokovno gimnazijo, osnovnošolski učni načrt za družbo). Ne glede na to, da je analiza učnih načrtov pokazala, da lahko v tretjo skupino uvrstimo največ učnih načrtov, velja poudariti, da je prisotnost vsebin slovenskega izseljenstva in diaspore v teh učnih načrtih minimalna (Ilc Klun, 2017). Kot nazoren primer naj vzamemo učne načrte za šolski predmet geografija. Osnovnošolski učni načrt za geografijo ne vključuje

2 V okviru kvantitativne analize učnih načrtov smo v posameznem učnem načrtu preštevali naslednje presojevalne kategorije (reference): selitve, izseljevanje, imigracija, vzroki selitev, migrant, emigrant, begunec, manjšina, multikulturalizem, migracije, odseljevanje, države izselitve, države priselitve, selivec, priseljenec, izseljenstvo, narod, medkulturnost, migracijski tokovi, emigracija, emigracijske države, imigracijske države, migracijska politika, imigrant, človekove pravice, državljanstvo, identiteta, preseljevanje, priseljevanje, meja, izseljenec, zdomec, diaspora, domovina. 
operativnih učnih ciljev s področja slovenskega izseljenstva in diaspore, kar pomeni, da formalno učitelj pri pouku geografije v osnovni šoli ni obvezan učiti tematike slovenskega izseljenstva in diaspore. V srednješolskem izobraževanju pa se v okviru splošnega, klasičnega in ekonomskega gimnazijskega programa pojavljajo v učnem načrtu trije operativni učni cilji, ki se nanašajo na področje slovenskega izseljenstva in diaspore:

1. »Dijaki izdelajo grafični prikaz števila slovenskih izseljencev po svetu v poljubni obliki« (Učni načrt. Geografija ..., 2008a, str. 33).

2. »Dijaki poznajo svetovni zemljevid slovenskih izseljencev in različne vzroke izseljevanja« (Učni načrt. Geografija ..., 2008a, str. 32).

3. „Dijaki v učbeniku ali literaturi iščejo podatke o najpogostejših vzrokih za priseljevanje in odseljevanje slovenskega prebivalstva po drugi svetovni vojni« (Učni načrt. Geografija ..., 2008a, str. 32).

Poudariti velja, da se od zgoraj navedenih operativnih učnih ciljev prvi nanaša na prvi letnik gimnazijskega izobraževanja, ostala dva pa na četrti letnik. To pomeni, da večina dijakov klasičnega, splošnega in ekonomskega gimnazijskega izobraževanja o slovenskem izseljenstvu spozna le, kje živijo slovenski izseljenci in razloge njihovega odseljevanja, le tisti, ki se odločijo za maturo iz predmeta geografija, pa s poukom geografije v gimnaziji dosežejo tudi preostala dva zapisana operativna učna cilja. Če je v klasični, splošni in ekonomski gimnaziji operativni učni cilj, ki je s področja poznavanja tematike slovenskega izseljenstva obvezen za vse dijake, na ravni prve in tretje klasifikacije učnih ciljev po Bloomu ${ }^{3}$ (priklic in uporaba: dijaki morajo poznati najprej številčnost slovenskih izseljencev po svetu, nato pa te podatke uporabiti pri izdelavi grafičnega prikaza številčne razporeditve slovenskega izseljenstva po svetu), se klasifikacija operativnih učnih ciljev, ki se navezujejo na področje slovenskega izseljenstva, v strokovni gimnaziji nekoliko nadgradi. Na tem nivoju gimnazijskega izobraževanja so za vse dijake v tretjem letniku obvezni trije operativni učni cilji, ki se nanašajo na področje slovenskega izseljenstva:

1. „Dijaki na karti sveta izdelajo kartogram števila slovenskih izseljencev« (Učni načrt. Geografija ..., 2008b, str. 11).

2. "Dijaki se vživljajo v položaj zdomca, izseljenca in priseljenca" (Učni načrt. Geografija ..., 2008b, str. 13).

3. »Dijak našteje najmanj dve državi, kjer živijo slovenski izseljenci in najmanj tri države, kjer živijo slovenski zdomci in jih pokaže na zemljevidu« (Učni načrt. Geografija ..., 2008b, str. 21).

Prvi in tretji operativni učni cilj se po revidirani Bloomovi taksonomiji učnih ciljev (Anderson, Krathwohl, 2001) nanašata na kognitivno področje in sta na nivoju priklica

3 Po Bloomovi taksonomiji iz leta 1956 lahko učne cilje razvrstimo v šest stopenj, ki si sledijo od najnižje do najvišje stopnje: znanje, razumevanje, uporaba, analiza, sinteza, vrednotenje. Najprej moramo v procesu vzgoje in izobraževanja doseči cilje nižjih taksonomskih stopenj, ki so podlaga za doseganje učnih ciljev višjih taksonomskih stopenj. Leta 2001 so Blomovo taksonomijo nekoliko revidirali in preoblikovali, tako da so šest stopenj znanja razvrstili v: priklic, razumevanje, uporaba, analiza, vrednotenje in ustvarjanje (Anderson, Krathwohl, 2001). Ni pomembno le to, da zna posameznik določen element vrednotiti, pač pa je za najvišjo stopnjo znanja pomembno ustvarjanje oziroma kreiranje novih elementov, novih spoznanj, novih znanj. 
in uporabe, medtem ko se drugi operativni učni cilj nanaša na konativno področje omenjene taksonomije.

Ker imajo pri realizaciji učnega načrta v vzgojno-izobraževalnem procesu pomembno vlogo tudi učila, ki jih učitelji in učenci (dijaki) uporabljajo pri pouku, smo se v okviru naslednje raziskave lotili vrednotenja vključenosti vsebin slovenskega izseljenstva in diaspore v šolska učila. V okviru raziskave smo analizirali 46 učbenikov in 8 samostojnih delovnih zvezkov za šolske predmete geografija, zgodovina in družba. Z raziskavo smo ugotovili, da nekateri učbeniki vključujejo vsebine slovenskega izseljenstva in diaspore tudi v primeru, če je to tematsko področje popolnoma izpuščeno iz učnega načrta, ki naj bi mu predmetni učbenik sledil. Takšni učbeniki so na primer nekateri osnovnošolski učbeniki za geografijo. Analiza geografskih učbenikov je pokazala, da osnovnošolski učbeniki za pouk geografije v 8 . in 9. razredu vključujejo vsebine slovenskega izseljenstva, ne glede na to, da jih osnovnošolski geografski učni načrt v okviru operativnih učnih ciljev ne predpisuje. Rezultati analize učbenikov so tako pokazali, da avtorji (recenzenti, uredniki) geografskih učbenikov smatrajo, da so vsebine slovenskega izseljenstva in diaspore pomembne za osnovnošolski pouk geografije ne glede na to, da jih operativni učni cilji osnovnošolskega učnega načrta za geografijo ne predpisujejo, in jih zato samoiniciativno vključujejo v učno vsebino svojih učbenikov. V tem primeru se nam zdi odločitev avtorjev (recenzentov, urednikov) geografskih učbenikov ključna, saj so v učbenikih našli mesto za vsebine slovenskega izseljenstva in diaspore (na podlagi vsebine širše zastavljenih splošnih učnih ciljev učnega načrta) in tako omogočili oziroma sploh dali možnost, da se te vsebine pojavijo pri pouku geografije (Ilc Klun, 2017).

Rezultati analiz učnih načrtov in šolskih učil (učbenikov in samostojnih delovnih zvezkov) so pokazali, da so vsebine slovenskega izseljenstva in diaspore v slovenski formalni vzgojno-izobraževalni okvir vključene minimalno oziroma po naši oceni nezadostno. Posledica tega je tudi izredno slabo poznavanje teh tematik s strani učencev in dijakov, kar je potrdila tudi raziskava, ki smo jo opravili med 1.103 učenci in dijaki slovenskih osnovnih in srednjih šol, v okviru katere nas je zanimalo znanje, razumevanje in zanimanje učencev in dijakov za vsebine slovenskega izseljenstva in diaspore. Rezultati raziskave so pokazali, da je znanje učencev in dijakov s področja omenjenih vsebin slabo. Na tem mestu naj v prvi vrsti omenimo slabo poznavanje osnovne terminologije, ki se nanaša tako na splošne migracijske procese kot tudi na področje slovenskega izseljenstva in diaspore. Po drugi strani pa smo z raziskavo tudi ugotovili, da je splošno znanje o slovenskem izseljenstvu in diaspori s strani anketiranih učencev in dijakov slabo. Na več kot $60 \%$ vprašanj, ki smo jih s področja poznavanja vsebin slovenskega izseljenstva in diaspore vključili v raziskavo, je večina anketiranih učencev in dijakov odgovorila $\mathrm{z} »$ ne vem «, kar pomeni, da vsebin slovenskega izseljenstva in diaspore ne poznajo. Ista raziskava je v nadaljevanju pokazala tudi, da 70,4 \% anketiranih učencev in dijakov meni, da bi bilo treba vsebinam slovenskega izseljenstva in diaspore nameniti v vzgojno-izobraževalnem sistemu več pozornosti, kar pomeni, da si želijo, da bi bile te vsebine v večji meri vključene v vzgojno-izobraževalni proces (Ilc Klun, 2017). Tako smo si zastavili izziv razviti učilo, na podlagi katerega lahko mlade poučujemo o vsebinah slovenskega izseljenstva in diaspore, da bi o teh tematikah dobili 
določeno znanje (ne le na nivoju priklica in uporabe, pač pa tudi višjih taksonomskih stopenj) in da bo zanje pridobivanje tega znanja zanimivo in jih bo pritegnilo za lastno, individualno raziskovanje tega vsebinskega področja.

\section{BIOGRAFSKO-NARATIVNI METODOLOŠKI PRISTOP ZA POUČEVANJEVSEBIN SLOVENSKEGA IZSELJENSTVA}

$\mathrm{S}$ pomočjo biografsko-narativnega metodološkega pristopa smo v okviru raziskave napisali 56 doživetih življenjskih zgodb pripadnikov slovenske diaspore, ki danes živijo v Združenih državah Amerike, Kanadi, Avstraliji in na Novi Zelandiji, in jih združili v skupno publikacijo »Zgodbe - velikokrat izrečene, a nikoli zapisane zgodbe ljudi slovenskih korenin iz Združenih držav Amerike, Kanade, Avstralije in Nove Zelandije « (Ilc Klun, 2017b). Vse zgodbe so resnične, so izpoved bodisi slovenskih izseljencev (prve generacije) ali tistih, ki so se rodili v omenjenih državah, in so se njihovi predniki (starši, stari starši ...) tja izselili iz Slovenije. Zbrane zgodbe so kratke, zanimive, napisane tako, da so namenjene najširši populaciji. Ker je bil prvotni namen zgodb njihova uporabnost v pedagoške namene, smo pri razvoju zgodb skrbno pazili na različna didaktična načela (primernost, nazornost, sistematičnost, diferenciacija, integracija, sodobnost, historičnost) in temu primerno oblikovali tudi zapis resničnih, doživetih življenjskih zgodb. V nadaljevanju predstavljamo primer življenjske zgodbe, ki je nastala kot končni rezultat biografsko-narativnega metodološkega pristopa.

\section{Tukaj so se mi odprla vrata v boljše življenje (Lucija)}

»Stara sem 82 let in sem zelo aktivna upokojenka, saj še vedno ves delavnik posvetim svojemu poslu, to je ukvarjanju z nepremičninami. Rodila sem se leta 1934 v Guči v Srbiji, saj je bil moj oče kot slovenski komandir policijske postaje takrat službeno premeščen v Gučo. Ko se je začela druga svetovna vojna, so šli vsi državni uslužbenci nazaj domov, tako smo se tudi mi vrnili v Sv. Jurij ob Pesnici. Doma sem nadaljevala osnovno šolanje, po končani osnovni šoli pa sem odšla v internat v Maribor, kjer me je mama vpisala na klasično gimnazijo. Gimnazijski program je med vojno trajal samo tri leta. Nemški okupatorji so nam takrat odpeljali očeta v zapor, kasneje so ga premestili v Nemčijo, od koder pa se ni več vrnil. V tem času, ko sem bila v internatu, torej med vojno, sta mama in sestra že odšli v Ameriko in si tam uredili bivališče s pomočjo moje tete in bratranca, ki sta bila že v Ameriki od konca prve svetovne vojne. Po koncu šolanja sem hotela oditi k mami samo na obisk. Uredila sem si vizo na ameriškem veleposlaništvu v Beogradu, mama pa mi je poslala garancijsko pismo ter denar in leta 1958 sem s parnikom iz pristanišča Le Havre v Franciji odplula v New York. Vožnja z ladjo je trajala sedem dni. Ko smo z ladje zagledali Statue of Liberty, so nam po zvočniku sporočili: "Pot v Ameriki se vam bo odprla le, če boste pridni in delavni«. Iz New Yorka sem se z vlakom odpeljala $v$ Kenosho, mesto v zvezni državi Wisconsin, kjer sta me pričakali mama in sestra. V Ameriki mi je bilo zaradi boljše gospodarske razvitosti, naprednosti, možnosti širšega razmišljanja, odprtih mej, ki so bile takrat v Jugoslaviji bolj ali manj zaprte, tako všeč, da sem sklenila ostati. Poleg tega sem imela doma tudi nekaj problemov s policijo, saj sem veliko »švercala« čez mejo (meso, poper, copate na zadrgo). Tako je bila moja odločitev, da ostanem v Ameriki, še trdnejša. Takoj sem se vpisala v večerno šolo, da sem se naučila jezika. V tem času sem se preživljala s pospravljanjem hiš in stanovanj premožnejših Judov. V dveh letih se mi je uspelo naučiti jezika tako dobro, da sem dobila službo v banki. Najprej sem delala na nižjem položaju, potem pa sem zaradi sposobnosti, pridnosti in delavnosti napredovala zelo visoko in kasneje 
preko dela spoznala tudi svojega bodočega moža. Moj mož, prvotno po poklicu psihiater, se je ukvarjal tudi $z$ oddajanjem nepremičnin in me je hitro vpeljal $v$ ta posel. Za pridobitev dodatnega znanja o poslovanju sem se vpisala še na trimesečni tečaj za poslovneže in začela počasi kupovati hiše ter jih oddajati. Kljub dodatnemu poslu sem na banki ostala sedem let, potem pa sem dobila zaposlitev kot tolmačka na sodišču, saj sem tekoče govorila srbsko in nemško. Državljanstvo sem prejela šele po petih letih, leta 1963. Pogoj, da si lahko dobil državljanstvo, je bil opravljen jezikovni tečaj. Ko sem se preselila v ZDA, mi ni bilo težko, saj smo si med seboj pomagali. Imela sem občutek, da so me ljudje spoštovali, sploh, ker sem bila pridna. Nikoli se nisem počutila kot tujec, saj smo bili v bistvu vsi priseljenci. V Kenoshi ni bilo tako izrazito »slovenskih ulic« oziroma območij s slovenskimi priseljenci kot v Clevelandu. Pa vendar smo se skupaj z drugimi jugoslovanskimi narodi našli v katoliški cerkvi, ki je bila zaslužna za pomoč priseljencem. Prav tako sem delovala v uredništvu glasila Prosvete. Pri meni doma smo organizirali razne sestanke, piknike in tako ohranjali slovensko dediščino. Jaz vedno pravim, da sem v prvi vrsti Slovenka, vendar pa se nazaj v Slovenijo ne bi nikoli preselila. Tukaj so se mi odprla vrata v boljše življenje. Zadošča mi, če jo obiščem enkrat letno, saj zelo rada vzdržujem stike s svojimi sorodniki in spremljam, kako se država razvija. Do sedaj sem bila na obisku že več kot dvajsetkrat. Imam dva otroka in enega mi je uspelo naučiti slovensko. Ta je tudi študiral v Sloveniji, vendar se je po koncu specializacije odločil, da se vrne nazaj v Ameriko. Nazaj se je vrnil z zdajšnjo ženo, ki je tudi Slovenka, žal pa onadva svojih sinov nista naučila govoriti slovensko. Danes sva v Kenoshi samo še dve Slovenki, ostali so namreč umrli ali pa so se zaradi študija ali zaposlitve preselili v večja mesta, kot je na primer Chicago.«

(Ilc Klun, 2017b)

Zgoraj predstavljeno osebno, doživeto življenjsko zgodbo lahko učinkovito uporabimo pri poučevanju in učenju o tematikah slovenskega izseljenstva. Preko prebrane življenjske zgodbe lahko učitelj z učenci in dijaki vodi razgovor tudi o naslednjih širših in ožjih vsebinskih poudarkih:

1. Razlogi izseljevanja: Iz zgodbe lahko spoznamo, da sta se Lucijina mama in sestra odselili v ZDA že v času druge svetovne vojne, njena njena teta in bratranec pa že v času po prvi svetovni vojni. V obeh primerih v zgodbi ni posebej izpostavljen razlog izselitve in priselitve, je pa izpostavljeno obdobje izselitve. Tako je iskanje razlogov za izselitev $v$ teh dveh primerih prepuščeno bralčevi interpretaciji. Po drugi strani pa iz zgodbe izvemo, da se je Lucija izselila v ZDA sprva iz osebnih razlogov, saj je načrtovala le obisk matere in sestre, kasneje pa se je zaradi drugih razlogov, kot je bila boljša gospodarska razvitost ZDA, naprednost, možnost širšega razmišljanja, njen obisk spremenil v stalno naselitev $\mathrm{v}$ ZDA.

2. Verižne migracije: Iz zgodbe lahko spoznamo, da družinske migracije najpogosteje potekajo po sistemu verižnih migracij, ko se sprva v neko državo, v našem primeru v ZDA, priselita en ali dva družinska člana, za njim pa se tja priselijo še ostali.

3. Migracijska dokumentacija: $\mathrm{V}$ sistemu legalnih migracij morajo imeti posamezniki urejeno tudi dokumentacijo, ki jim dovoljuje naselitev v določeni državi. V našem primeru si je za svoj obisk (sprva ni bil načrtovan kot trajna naselitev) Lucija morala urediti vizum na ameriškem veleposlaništvu v Beogradu. Brez pridobljenega vizuma Luciji ne bi bil dovoljen vstop v ZDA. Prav tako je za vstop v ZDA Lucija potrebovala t. i. garancijsko pismo, ki ji ga je posredovala njena mama. Slovenski izseljenci so tako kot številne druge etnične skupine za vstop v ZDA potrebovali garancijsko 
pismo, v katerem je moral tisti, ki je garancijsko pismo izdal (sorodnik ali prijatelj oziroma znanec), zagotoviti, da oseba, ki se želi priseliti v ZDA, ne bo v breme ameriški državi, saj ima v ZDA zagotovljeno bivanje (stanovanje, prenočišče) in vsakdanje življenje (hrana, delo). Brez garancijskega pisma je bil vstop v ZDA novim priseljencem praktično nemogoč.

4. Migracijske poti: Iz izhodišča do destinacije morajo migranti načrtovati svojo pot. Še v obdobju po drugi svetovni vojni je največ slovenskih izseljencev potovalo $\mathrm{v}$ ZDA z ladijskimi prevozniki, ki so proti ZDA vozili iz različnih evropskih pristanišč. Lucija si je za svojo evropsko izhodiščno luko izbrala pristanišče Le Havre v Franciji, od koder je potrebovala sedem dni plovbe do New Yorka. Večina evropskih ladijskih prevoznikov je do sredine 50. let 20. stoletja priseljence pripeljala do New Yorka, zato je večina evropskih priseljencev prvič prišla v stik s severnoameriškim kontinentom v mestu New York, kjer so najprej uzrli kip svobode, kar v svoji zgodbi opiše tudi Lucija. Na tem mestu velja tudi poudariti, da so med leti 1892 do leta 1954 večino evropskih priseljencev, ki so se želeli priseliti v ZDA, najprej prepeljali na Ellis Island (po nekaterih podatkih naj bi samo v obdobju od 1892 do 1924 na otok prispelo okoli 24 milijonov priseljencev; Bandiera, Rasul, Viarengo, 2013), kjer so bili podvrženi temeljitim zdravniškim pregledom, ki so jim bodisi omogočili ali pa zaradi postavljene zdravniške diagnoze onemogočili vstop in s tem priselitev v ZDA.

5. Proces integracije: Večina slovenskih priseljencev, ki so se v ZDA priselili v obdobjih do konca druge svetovne vojne, je svojo prvo zaposlitev našla kot nekvalificirana delovna sila, saj za opravljanje drugega dela niso imeli ustrezne izobrazbe, izkušenj na ameriškem trgu dela, ena izmed ključnih omejitev za opravljanje bolje plačanih del pa je bilo tudi neznanje angleškega jezika. Ob pridobitvi ustrezne izobrazbe, znanju angleškega jezika, pa so lahko tudi slovenski priseljenci karierno (poklicno) napredovali. To v svoji zgodbi poudari tudi Lucija, saj je ob priselitvi v ZDA pričela z delom hišne pomočnice (pospravljavke), $z$ dokončanjem večerne šole, priučenjem angleškega jezika in z delovnimi izkušnjami, pa je tudi karierno napredovala do tolmačke na sodišču in nepremičninske agentke.

6. Proces formalnega vključevanja v novo socialno okolje: Ključni element vključevanja v novo socialno okolje je znanje jezika okolja priselitve in vključevanje $\mathrm{v}$ družbeno strukturo novega okolja. Ta proces v svoji zgodbi opiše tudi Lucija, saj poudari pomen znanja angleškega jezika tudi pri pridobivanju novega pravnega statusa, državljanstva ZDA.

7. Pomen etničnih skupnosti v novem socialnem okolju: Pri vključevanju v novo socialno okolje so bistvenega pomena tudi etnične skupnosti priseljencev, saj se v okviru teh skupnosti novi priseljenci v novem socialnem okolju počutijo bolj varne, posamezniki, ki so se v to okolje priselili pred njimi, jim s svojimi izkušnjami pomagajo, obenem pa etnične skupnosti skrbijo za ohranjanje svojih kulturnih posebnosti. Lucija v svoji zgodbi opiše, da se sama v novem socialnem okolju ni nikoli počutila kot tujka, ker je bila obdana s številnimi priseljenci, poleg tega pa so ji pri vključevanju v novo okolje pomagali drugi slovenski priseljenci, ki so se v ZDA priselili že pred njo. Zaradi želje po ohranitvi svoje slovenske etnične pripadnosti se je tudi sama 
vključila v dve slovenski skupnosti - slovensko cerkev in uredništvo slovenskega glasila Prosveta. V svoji zgodbi poudari pomen srečanj, sestankov in t. i. piknikov v okviru slovenskih etničnih društev. Z aktivnim vključevanjem v etnična društva priseljenci ohranijo stik s svojim izvornim etničnim okoljem (v našem primeru s Slovenijo) in skrbijo za ohranjanje kulture tega okolja (na primer slovenski jezik, slovenski običaji in navade, folklorne navade, glasba ipd.). V svoji zgodbi Lucija tudi na kratko primerja slovensko etnično skupnost v Kenoshi, katere članica je tudi sama, s slovensko etnično skupnostjo v Clevelandu, ki je zaradi svojega obsega in delovanja, specifična slovenska socialna struktura v ZDA.

8. Poudarjanje etnične identitete med priseljenci: Ne glede na aktiven proces vključevanja v novo socialno okolje, zadovoljstvo nad novim socialnim okoljem, večina pripadnikov prve generacije izseljencev poudarja svoje izvorno etnično okolje z izpostavljanjem etnične identitete tega okolja. Lucija v svoji zgodbi poudari svojo slovensko etnično identiteto z besedami: »Jaz vedno pravim, da sem v prvi vrsti Slovenka«. Poudarjanje slovenske identitete med pripadniki slovenske diaspore v ZDA je še vedno zelo pomembno, saj svoje slovenske identiteto ne poudarjajo le pripadniki prve generacije izseljencev (torej tisti, ki so se sami izselili z območja današnje Slovenije), pač pa tudi pripadniki druge, tretje, celo pete generacije (Ilc, 2006).

9. Posledice zamiranja migracijskega toka: Dejstvo je, da so bile ZDA v obdobju od konca 19. stoletja do konca 2. svetovne vojne ena izmed ključnih končnih destinacij slovenskih izseljencev. Najbolj intenzivni emigracijski tok Slovencev v ZDA je bil v zadnjem desetletju 19. stoletja in v prvem desetletju 20. stoletja, ki mu je sledil po obsegu veliko manjši emigracijski tok konec 2 . svetovne vojne. Potem pa se je postopoma tako zaradi političnih kot gospodarskih razlogov emigracijski tok Slovencev v ZDA ustavil. Zaradi tega se je na primeru slovenske diaspore vse do danes zmanjševalo število pripadnikov prve generacije, naraščalo pa število pripadnikov vseh naslednjih generacij (druge, tretje, četrte, pete). To v svoji zgodbi poudari tudi Lucija, saj omeni, da sta danes v Kenoshi, v mestu, kjer živi, samo še dve Slovenki.

Ob zgodbi, ki je nastala kot rezultat biografsko-narativnega metodološkega pristopa, smo zgoraj poudarili devet vsebinskih področij slovenskega izseljenstva, ki jih lahko navežemo tudi na globalne migracijske procese. Posameznik lahko torej ob branju resnične življenjske zgodbe na nevsiljiv način spoznava, razume in vrednoti življenje migrantke - na eni strani emigrantke in na drugi imigrantke. Ob zgodbi lahko z dodatno učiteljevo razlago spoznava pretekle globalne in slovenske migracijske procese, jih vrednoti in jih povezuje ter navezuje na današnje migracijske trende.

\section{SKLEP}

Zaradi obsega slovenskega izseljenstva je po našem mnenju potrebno tematikam slovenskega izseljenstva nameniti posebno mesto tudi v vzgojno-izobraževalnem sistemu. Primerna obravnava omenjenih vsebin bi namreč lahko pomembno prispevala k celovitemu pogledu na sodobne in pretekle migracijske procese, spoštovanju različnosti med 
posameznimi migracijskimi skupinami in nenazadnje tudi k poznavanju, razumevanju in spoštovanju slovenske diaspore. Vsebino slovenskega izseljenstva lahko prenesemo tudi na sodobne globalne migracijske procese in tiste, ki so neposredno vezani na prostor današnje Slovenije. Nenazadnje so migracije sodoben družbeni pojav, ki vpliva na vse sfere družbe in države in bi tako vsebina migracij, in s tem tudi slovenskega izseljenstva, morala postati ena izmed pomembnih obveznih učnih vsebin sodobnega izobraževanja mladih. Vsekakor se v sklopu poučevanja postavlja vprašanje, s pomočjo katerih učnih poudarkov in učnih metod naj učitelj v šoli predstavi tematiko slovenskega izseljenstva, da bo ta mlade pritegnila in morda tudi navdušila za lastno raziskovanje. Eden izmed učinkovitih pristopov je biografsko-narativni metodološki pristop, katerega končni rezultat so življenjske zgodbe (migrantov - emigrantov in imigrantov), ki že zaradi svoje resničnosti, preproste pripovedi in življenjskih situacij pritegnejo bralca. Zaradi zapisa $\mathrm{V}$ prvi osebi ednine imajo večjo pripovedno moč, bralec dobi občutek, kot da oseba svojo doživeto življenjsko zgodbo pripoveduje njemu, hkrati pa že zaradi strukture zgodbe učeči se nima občutka, da bi se ob branju zgodbe učil učno vsebino. Življenjske zgodbe so tako lahko pomembno izhodišče za učenje nove učne vsebine, učitelj pa mora v nadaljevanju vsebino zgodbe povezati s koncepti, pojmi in procesi, ki se povezujejo z migracijami. Prav tako zgodba omogoča razmišljanje o globalnih migracijskih trendih in aplikaciji slovenskega izseljenstva na sodobne migracijske procese.

\section{Viri in literatura}

Anderson, L. W., Krathwohl, D. R., 2001. A taxonomy for learning, teaching and assessing. URL: https://www.apu.edu/live_data/files/333/blooms_taxonomy_action_ verbs.pdf (citirano 1. 2. 2018).

Bamberg, M., 2011. Who am I? Narration and its contribution to self and identity. Theory \& Psichology, 21 (1), str. 3-24. DOI: 10.1177/0959354309355852.

Bandiera, O., Rasul, I., Viarengo, M., 2013. The making of modern America: Migratory flows in the age of mass migration. Journal of development economics, 102, str. $23-47$.

Bellwood, P., 2013. First migrants. Ancient migration in global perspective. Chichester, Wiley Blackwell, 308 str.

Blix, B. H., Hamran, T., Normann, H., K., 2013. Struggles of being and becoming: A dialogical narrative analysis of the life stories of Sami elderly. Journal of aging studies, 27, str. 264-275. DOI: 10.1016/j.jaging.2013.05.002.

Blix, B., H., Hamran, T., Normann, H., K., 2015. Roads not taken: A narrative positioning analysis of older adults' stories about missed opportunities. Journal of aging studies, 35 , str. $169-177$.

Castles, S., Miller, M., 2009. The age of migration. International population movements in the modern world, 4th ed. Basingstoke, London, Macmillan Press, 369 str.

Crivello, G., 2015. There's no future here: The time and place of children's migration aspirations in Peru. Geoforum, 62, str. 38-46. 
Drnovšek, M., 1991. Pot slovenskih izseljencev na tuje. Ljubljana, 207 str.

Ilc, M., 2006. Ameriški Slovenci ali Američani s slovenskimi koreninami v metropolitanskem območju Clevelanda. Diplomsko delo. Univerza v Ljubljani, Filozofska fakulteta, Oddelek za geografijo, 90 str.

Ilc Klun, M., 2014. Teoretična in terminološka izhodišča izseljenstva ter poznavanje tematik izseljenstva med slovenskimi učenci in dijaki. Dela, 41, str. 165-181.

Ilc Klun, M., 2017. Slovensko izseljenstvo in diaspora v procesu geografskega izobraževanja. Doktorska disertacija. Univerza v Ljubljani, Filozofska fakulteta, Oddelek za geografijo, 339 str.

Ilc Klun, M., 2017b. Zgodbe - velikokrat izrečene, a nikoli zapisane zgodbe ljudi slovenskih korenin iz ZDA, Kanade, Avstralije in Nove Zelandije. Ljubljana, 133 str.

International migration report 2015. 2016. New York, United Nations, Department of Economic and Social Affairs, Population Division, 36 str.

Klemenčič, M., 1995. Slovenes of Cleveland. Novo mesto, Dolenjska založba, 414 str.

Kovač, B., 2003. Globalizacija, migracijski tokovi in ekonomski razvoj na obrobju slovenskih migracijskih dilem. V: Migracije - globalizacija - Evropska unija. Ljubljana, Mirovni inštitut, 350 str.

Laoire, C. N., 2007. The green green grass of home? Return migration to rural Ireland. Journal of rural studies, 23, 3, str. 332-344. DOI: 10.1016/j.jrurstud.2007.01.005.

Meares, C., 2010. A fine balance: Women, work and skilled migration. Women's studies international forum, 33, 5, str. 473-481. DOI: 10.1016/j.wsif.2010.06.001.

Pajnik, M., Bajt, V., 2009. Biografski narativni intervju: aplikacija na študije migracij. Dve domovini, 30, str. 69-89.

Pajnik, M., Zavratnik Zimic, S., 2003. Med lokalnim in globalnim v sodobnih migracijah. V: Migracije - globalizacija - Evropska unija. Ljubljana, Mirovni inštitut, 350 str.

Papademetriou, D. G., 2007. The Age of Mobility. How to get more out of migration in the 21 st century. Migration Policy Institute, 29 str.

Randall, W., Baldwin, C., McKenzie-Mohr, S., McKim, E., Furlang, D., 2015. Narrative and resilience: A comparative analysis of how older adults story their lives. Journal of aging studies, 34, str. 155-161. DOI: 10.1016/j.jaging.2015.02.010.

Roseneil, S., 2012. Using biographical narrative and life story methods to research women's movements: FEMCIT. Women's studies international forum, 35, 3, str. 129-131.

Russell, P., 2012. Using biographical narrative and life story methods to research women's movements: Sisterhood and after. Women's studies international forum, 35, 3, str. 132-134.

Salzmann, T., Edmonston, B., Raymer, J., 2010. Demographic Aspects of Migration. Wiesbaden, VS Verlag, 351 str.

Učni načrt. Družba - osnovna šola. 2011. Ljubljana, Zavod RS za šolstvo, 21 str.

Učni načrt. Državljanska in domovinska vzgoja ter etika - osnovna šola. 2011. Ljubljana, Zavod RS za šolstvo, 22 str.

Učni načrt. Geografija - splošna, klasična in ekonomska gimnazija. 2008a. Ljubljana, Zavod RS za šolstvo, 62 str. 
Učni načrt. Geografija - strokovna gimnazija. 2008b. Ljubljana, Zavod RS za šolstvo, 28 str. Učni načrt. Sociologija - gimnazija. 2008. Ljubljana, Zavod RS za šolstvo, 23 str. Učni načrt. Zgodovina - osnovna šola. 2011. Ljubljana: Zavod RS za šolstvo, 45 str. Wengraf, T., 2004. The Biographic-Narrative Interpretive Method (BNIM). London, University of East London, 32 str.

Willemse, K., 2014. Everything I told you was true: The biographic narrative as a method of critical feminist knowledge production. Women's studies international forum, 43, str. 38-49.

\section{BIOGRAPHIC-NARRATIVE METHODOLOGICAL APPROACH FOR TEACHING AND UNDERSTANDING THE CONTENTS OF SLOVENIAN EMIGRATION}

\section{Summary}

Due to the size of Slovenian diaspora, in our opinion, it is necessary to devote special attention to the topics of Slovenian emigration in the educational system. With an appropriate approach and inclusion of the topics about Slovenian emigration into Slovenian educational system we could contribute to a comprehensive view of nowadays and past migration processes, that individual would respect diversity among different migration groups and last, but not least, to better understanding and knowledge about Slovenian diaspora. The contents of Slovenian emigration can also be transferred to contemporary global migration processes and those that are directly related to the territory of nowaday's Slovenia. Migration is a modern social phenomenon that affects all spheres of society and the state and thus the content of migration, and consequently the content of Slovenian emigration, should become an important learning content of youth education. When teaching about Slovenian emigration, the following questions arise: 1) which contents about Slovenian emigration should teacher teach in schools and 2) through which teaching methods teacher should teach the contents about Slovenian emigration in order to motivate young people to learn about that contents and to motivate them for their own research. One of the effective approaches is biographic-narrative methodological approach (BINM approach), as one of the results of that approach is a life story of a migrant (emigrant and immigrant). Life stories attract readers by their reality, simple narratives and real life situations. Because they are written in the first person, life stories have greater narrative power, the reader gets a feeling that a person tells his life story to him/her. At the same time, because of the structure of the life story, the reader does not have the feeling that when reading the story s/he is studying the learning content. Life stories can thus be an important starting point for learning new learning content, and the teacher must then link the story to the concepts and processess that relate to migration. The story also allows thinking about global migration trends and the connection of Slovenian emigration flows to modern migration processes. 